\title{
TENDÊNCIAS DE PESQUISA SOBRE MUSEUS E INFORMAÇÃO NO BRASIL: UM ESTUDO CIENCIOMÉTRICO A PARTIR DOS ANAIS DO ENANCIB
}

\author{
RESEARCH TRENDS ON MUSEUMS AND \\ INFORMATION IN BRAZIL: A SCIENTOMETRIC STUDY \\ FROM THE ANNALS OF THE ENANCIB
}

Larissa Fernandes Dutra ${ }^{a}$

Marlusa de Sevilha Gosling b

\begin{abstract}
RESUMO
Introdução: A relação entre museus e informação é destacada mundialmente a partir de 1970, quando foram agregados significados aos objetos museológicos que ampliaram suas funções, a exemplo da percepção da capacidade destes em transmitir informações variadas ao público. A partir daí, cientistas ligados tanto ao estudo de museus quanto a pesquisa em informação, começaram a desenvolver investigações relacionando ambas áreas do conhecimento. Objetivo: Assim, o objetivo deste artigo é compreender as principais tendências de pesquisa sobre museus e informação no Brasil. Metodologia: Para isso, realizou-se um estudo cienciométrico a partir dos anais do Encontro Nacional de Pesquisa em Ciência da Informação, desde 2007 até 2019. Um banco de dados composto por 180 produções científicas fora gerado e importado para o software NVivo. O uso do programa aprimorou a análise do banco, possibilitando a construção de conhecimentos a partir das informações recolhidas. Resultados: Através dos resultados identificou-se a existência de uma tendência ascendente quanto ao número de publicações ligadas ao tópico museus e informação no evento nos últimos anos. Observou-se uma desigualdade de produtividade entre os autores que estudam o tema, pois poucos são responsáveis pela maior parte da literatura. Viu-se, ainda, que as pautas de maior interesse entre os pesquisadores deste campo são a da Documentação Museológica e dos Museus Virtuais. Conclusões: $O$ artigo elucida possibilidades de novos roteiros de investigação, podendo auxiliar no desenvolvimento de políticas de incentivo para o fomento de pesquisas que ainda não foram, mas precisam ser realizadas em se tratando do tema museus e informação.
\end{abstract}

Descritores: Museus. Informação. Produção Textual Científica.

\footnotetext{
a Doutoranda em Gestão e Organização do Conhecimento pela Escola de Ciência da Informação da Universidade Federal de Minas Gerais (UFMG). E-mail: larissadutraa@gmail.com

b Doutora em Administração pela Universidade Federal de Minas Gerais (UFMG). Docente de de Marketing da Universidade Federal de Minas Gerais (UFMG). E-mail: mg.ufmg@gmail.com
} 


\section{INTRODUÇÃO}

A relação entre os campos do conhecimento Museologia e Ciência da Informação $(\mathrm{Cl})$, segundo Santos (2011), é enfatizada a partir da corrente da Nova História nos anos 1970, quando passam a ser agregados ao objeto museológico novos significados que ampliam suas atribuições, colocando-o como um documento, que transmite uma mensagem, uma informação. $O$ objeto, assim, passa a ser considerado sob novos aspectos, afirmando a sua capacidade de comunicar e produzir conhecimento.

Para Santos (2011), através da gestão da memória, da produção da informação documentária e da mediação da informação, os museus passaram a ser reconhecidos como especializadas unidades de informação, não dedicadas somente a conservação de objetos, mas também a difusão de sua história. A partir de então, pesquisadores ligados tanto ao estudo e entendimento do fenômeno museus, quanto aqueles que se debruçavam para analisar elementos ligados a informação, iniciaram também o desenvolvimento de pesquisas relacionando ambas áreas do conhecimento.

No Brasil, em específico, a relação entre Museologia e Informação não pode ser vista distanciada do Encontro Nacional de Pesquisa em Ciência da Informação (ENANCIB). Esses encontros - que reúnem pesquisadores em grupos de trabalho (GT) no intuito de apresentar e discutir investigações finalizadas e em andamento em $\mathrm{Cl}$ - se configuram como um dos mais importantes locais de debate sobre esta área do conhecimento no país.

A inserção da Museologia como temática de estudo no ENANCIB atevese, a princípio, à abertura de "Debates sobre Museologia e Patrimônio", no ano de 2007. Porém, somente em 2009 fora criado um grupo de trabalho específico relacionado a esse saber, através do GT9: Museu, Patrimônio e Informação, que foi responsável por estabelecer, desde então, um campo de estudos em evento destinado a compreender a relação entre a Museologia e a Ciência da Informação no país.

A partir deste momento, começaram a surgir, cada vez mais, investigações associadas ao entendimento da relação entre esses dois campos 
do conhecimento. Pesquisadores brasileiros envolvidos com a temática denotaram o seu interesse publicando, progressivamente, conteúdos no ENANCIB. Por este motivo, o presente artigo propõe entender quais são as principais tendências de pesquisa sobre a temática de museus e informação desde a sua aparição no encontro em 2007 até o ano de 2019.

Justifica-se a necessidade deste estudo, pois, segundo Oliveira et al (1992), a avaliação do entendimento do progresso e produtividade científica em uma área do conhecimento deve ser um dos elementos principais para o estabelecimento e acompanhamento de uma política nacional de ensino e pesquisa, uma vez que permite um diagnóstico das reais potencialidades de um saber em específico.

Nesse sentido, realizou-se um estudo cienciométrico a partir de investigações contempladas nos anais do ENANCIB. Os passos metodológicos foram divididos em quatro momentos principais, sendo eles: 1) busca de produções científicas relevantes para o estudo cienciométrico; 2) seleção e recuperação das investigações de interesse e criação de um banco de dados; 3) organização dos dados obtidos através do software NVivo; 4) análise dos resultados e elaboração das considerações finais.

O artigo, desse modo, está organizado em cinco seções principais: inicialmente é introduzida a análise cienciométrica como o método de trabalho, seu histórico e características principais são delineados. Em seguida, é apresentado o evento ENANCIB e a sua dinâmica é discutida brevemente. A partir de então, a metodologia de pesquisa é descrita e nos dois últimos momentos, são apresentados, respectivamente, os resultados do estudo e as considerações finais dos autores.

\section{CIENCIOMETRIA: A "CIÊNCIA DA CIÊNCIA"}

Nas últimas décadas, acompanhando a expansão da ciência e da tecnologia, tornou-se cada vez mais evidente a necessidade de avaliação dos níveis de desenvolvimento alcançados pelas múltiplas disciplinas do conhecimento científico mundial. Isso porque, a medição da produtividade dos centros de pesquisa, dos investigadores individuais e das universidades, tem 
possibilitado o entendimento do avanço de diferentes áreas do saber, contribuindo com a delimitação das temáticas mais promissoras e, consequentemente, com as prioridades na alocação de recursos por parte de instituições variadas, como a Organização para a Cooperação e o Desenvolvimento Econômico (OCDE), por exemplo. Além disso, esses indicadores têm viabilizado o estudo comparativo do desenvolvimento científico entre países e continentes (VANTI, 2002).

Nesse sentido, a avaliação e medição de um determinado ramo do conhecimento permite - quando métodos confiáveis e sistemáticos são utilizados - mostrar à sociedade como tal domínio vem se desenvolvendo e de que forma tem contribuído para resolver os problemas que se apresentam dentro de sua área de abrangência. Como resultado, a partir deste tipo de observação, a comunidade acadêmica pode identificar as lacunas de desenvolvimento científico em seus campos de estudo, tal como os hot topics, ou seja, os temas mais pesquisados e em maior ascensão.

Assim, com o passar dos anos e o aumento do interesse em diagnosticar cientificamente algumas áreas do conhecimento, foram desenvolvidos métodos quantitativos voltados para a avaliação da ciência e seus fluxos de informação. Para Vanti (2002), esses métodos podem ser exemplificados por quatro tipos principais: a Bibliometria, a Informetria, a Webometria e a Cienciometria, que, de modo geral, possuem funções semelhantes, mas, ao mesmo tempo, propõem medir o conhecimento científico sob enfoques distintos.

A Bibliometria, por exemplo, estuda os aspectos quantitativos da produção, disseminação e uso da informação registrada, detendo como objeto principal a análise de livros, documentos e revistas, determinando, assim, seus números de empréstimos, volume de citações, medição da produtividade dos autores, etc. Os indicadores informétricos, por sua vez, oferecem possibilidades para quem deseja explorar um universo de objetos e sujeitos ainda mais amplo, não se limitando apenas à informação registrada, dado que pode analisar também os processos de comunicação informal, inclusive falada, e dedicar-se a pesquisar os usos e necessidades de informação de grupos sociais desfavorecidos, e não só de elites intelectuais, por exemplo. A Webometria 
quantifica o crescimento ou perda de importância relativa de um tema no ciberespaço. Permite mensurar o volume das citações entre páginas na web, possibilitando aferir a importância de um site que aborda uma certa temática em comparação com outros que discutam o mesmo conteúdo (VANTI, 2002).

O último subcampo que propõe diagnosticar uma determinada área da Ciência - nomeado Cienciometria - possui, historicamente falando, como precursores de sua utilização pesquisadores europeus. Dobrov e Karennoi (1969) foram um dos primeiros autores a utilizarem o termo em publicação do All Union Institute for Scientific and Technical Information (VINITI). As primeiras definições desse subcampo consideravam-no como a medição do progresso informático, onde o termo "informático" significava a disciplina do conhecimento que estuda a estrutura e as propriedades da informação científica e as leis do processo de comunicação.

Ainda na mesma década, o físico e historiador inglês Derek Price (1964) estudou e descreveu a evolução da Ciência em publicação intitulada Little Science, Big Science, onde ponderou sobre a aplicação de métodos científicos para explicar o desenvolvimento de saberes diversos. Como físico, Price (1964) construiu uma analogia sobre o universo do estudo de uma ciência e a teoria da termodinâmica. Para o autor, em resumo, ao analisar uma ciência é fundamental:

a) Mensurar qual é o seu volume - ou seja, a quantidade, em números, do que tem sido produzido, quais os assuntos mais estudados e as suas lacunas;

b) Entender e explicar em que velocidade se faz a distribuição de suas 'moléculas' - em outras palavras, compreender a cadência da comunicação científica, como tem sido divulgada a produção dos pesquisadores nas revistas e eventos das diferentes áreas do conhecimento;

c) Identificar de que forma estas 'moléculas' interagem entre si - ou seja, como os autores contribuem uns com os outros para o desenvolvimento das pesquisas científicas e quais são as principais pontes de conexão entre as disciplinas; 


\title{
d) Definir qual é a derivação das propriedades políticas e sociais desse
} 'gás' - isto é, entender a relação entre ciência e política e quais as consequências sociais dos estudos em desenvolvimento.

Com a publicação, Price (1964) teorizou a pesquisa metodológica da ciência por ela mesma e preconizou a ideia de uma nova Ciência: "a Ciência da Ciência", definida como "Cienciometria" (BERTUZZO, 2004).

Com o desenrolar dos anos e o desenvolvimento de investigações, cada vez mais, dedicadas a estudos cienciométricos, a sua definição fora ganhando novas características, progredindo conforme o aumento das utilidades de sua aplicação:

\begin{abstract}
A Cienciometria estuda, por meio de indicadores quantitativos, uma determinada disciplina da ciência. Estes indicadores quantitativos são utilizados dentro de uma área do conhecimento, por exemplo, mediante a análise de publicações, com aplicação no desenvolvimento de políticas científicas. Tenta medir os incrementos de produção e produtividade de uma disciplina, de um grupo de pesquisadores de uma área, a fim de delinear o crescimento de determinado ramo do conhecimento (TAGUE-SUTCKIFFE,1992, p. 2)
\end{abstract}

Desta forma, percebe-se que a partir de um estudo cienciométrico é possível que se identifique não somente as tendências de pesquisa e o crescimento do conhecimento científico em uma área do saber, mas também a dispersão e obsolescência da literatura científica; a produtividade e o grau de colaboração entre pesquisadores; o surgimento de novos temas de trabalho; os níveis de publicação e alcance de periódicos científicos e inúmeras outras possibilidades que sejam de interesse de aprofundamento dos pesquisadores envolvidos no estudo. É devido a essas possibilidades que o método foi o escolhido para a realização da presente pesquisa. Além disso, os seus objetos, variáveis e objetivos (conforme Quadro 1) parecem ser os que mais atendem aos propósitos desta investigação.

\section{Quadro 1: A aplicação cienciométrica}

\begin{tabular}{|c|l|}
\hline Objeto de estudo & Disciplinas, assuntos, áreas e campos científicos e tecnológicos. \\
\hline Variáveis & $\begin{array}{l}\text { Como os cientistas se comunicam. Como uma área de estudo tem se } \\
\text { desenvolvido. }\end{array}$ \\
\hline Métodos & Análise de co-ocorrência de termos, expressões, palavras-chave, etc. \\
\hline Objetivos & $\begin{array}{l}\text { Identificar domínios de interesse. Onde os assuntos estão } \\
\text { concentrados. }\end{array}$ \\
\hline
\end{tabular}

Fonte: Adaptado de Vanti (2002) 
Nesse sentido, o escopo do presente artigo pauta-se na aplicação de uma pesquisa cienciométrica considerando como principal objeto investigativo 0 campo de estudo "museus e informação". O interesse em se diagnosticar e analisar esse domínio do conhecimento deve-se a intenção de elucidação das possibilidades de novos roteiros de estudo nos campos de Museologia e Ciência da Informação. Os resultados apresentados poderão auxiliar, por exemplo, no desenvolvimento de políticas de incentivo para o fomento de pesquisas que ainda não foram, mas precisam ser realizadas em se tratando do quesito informação em museus, contribuindo, quem sabe, para o desenvolvimento dessas instituições culturais, assim como, para o bem-estar de seu visitante.

Com isso, para o desenvolvimento do diagnóstico cienciométrico proposto neste artigo utilizou-se o ENANCIB como fonte de busca para a recuperação de investigações relacionadas ao tema. Assim, para o melhor entendimento do evento e sua dinâmica a seção seguinte se prestará a um breve resumo deste.

\section{O ENCONTRO NACIONAL DE PESQUISA EM CIÊNCIA DA INFORMAÇÃO}

O ENANCIB é um evento científico, de periodicidade anual - salvo algumas exceções - promovido pela Associação Nacional de Pesquisa e PósGraduação em Ciência da Informação (ANCIB). O fórum aborda a discussão de pesquisas - trabalhos finalizados e em andamento - em CI no Brasil.

O encontro, nesse sentido, se configura como um dos mais importantes debates sobre Ciência da Informação do país, ocorrendo desde 1994 e reunindo pesquisadores renomados e discentes dos programas de Pós-graduação em $\mathrm{Cl}$ de diversas instituições brasileiras (PORTAL ENANCIB, 2020). Desde o seu primeiro ano, passou por universidades localizadas nas mais variadas cidades, como Belo Horizonte - MG, Rio de Janeiro - RJ, Brasília - DF, Salvador - BA, João Pessoa - PB, dentre muitas outras.

No evento, pesquisadores se reúnem em 11 grupos de trabalho sobre diferentes temas especializados na área, sendo eles: GT1: Estudos Históricos e Epistemológicos da Cl; GT2: Organização e Representação do Conhecimento; GT3: Mediação, Circulação e Apropriação da Informação; GT4: Gestão da Informação e do Conhecimento; GT5: Política e Economia da Informação; GT6: 
Informação, Educação e Trabalho; GT7: Produção e Comunicação da Informação em Ciência, Tecnologia \& Inovação; GT8: Informação e Tecnologia; GT9: Museu, Patrimônio e Informação; GT10: Informação e Memória e GT11: Informação e Saúde.

Os grupos de trabalho, entretanto, nem sempre existiram conforme descrição anterior. A Museologia, por exemplo, é inserida oficialmente como tema no evento somente em 2007 - 14 anos após a primeira conferência restringindo-se a um tópico de discussão denominado "Debates sobre Museologia e Patrimônio", não possuindo, naquela época, um GT próprio. Somente em 2009 fora criado o GT9: Museu, Patrimônio e Informação, formalizando-se, desde então, um campo teórico-conceitual de estudos conectando a Museologia junto à Ciência da Informação.

Nesse sentido, de 2007 até o ano de 2019, totalizam-se 13 anos de produção científica relacionada as áreas de museus e informação no evento, significando que - a nível de Brasil - é indispensável a contemplação dos ENANCIB's quando do interesse de se investigar qualquer problemática relacionada a esses campos do conhecimento.

Desse modo, na seção seguinte, serão expostos os passos metodológicos utilizados para a realização do estudo proposto e, posteriormente, serão apresentados os resultados de pesquisa.

\section{METODOLOGIA}

Os passos metodológicos desta investigação se resumem em quatro momentos principais, conforme observado na Figura 1.

Figura 1: Passo a passo metodológico

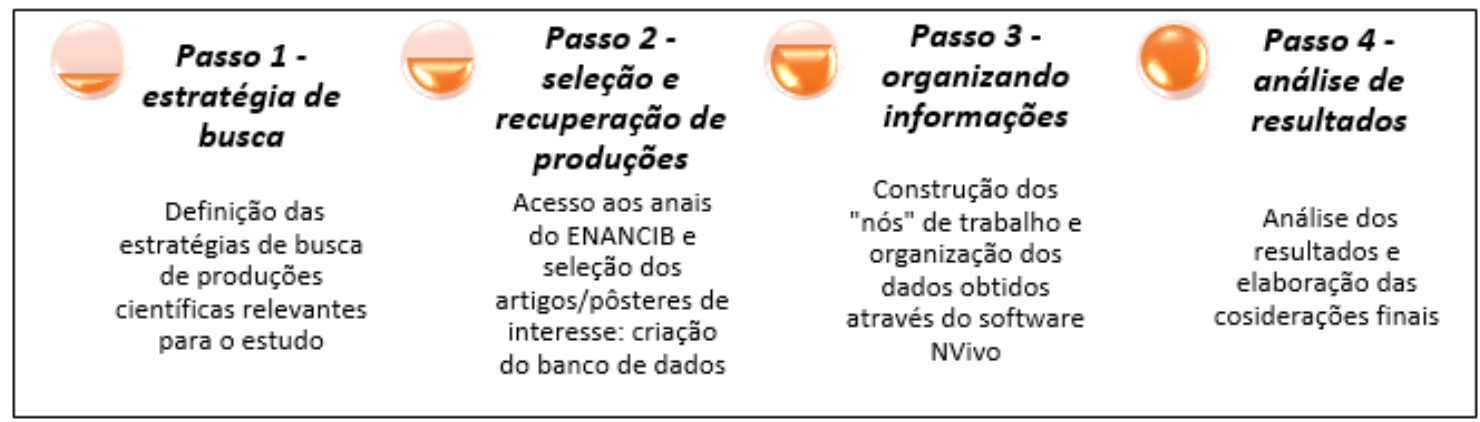

Fonte: Elaboração própria (2020) 
Inicialmente, no Passo 1, foram definidas as estratégias de busca das produções científicas do evento ENANCIB que atendessem aos objetivos do estudo proposto. Para isso, foi utilizado o método do vetor de pesquisa, que, segundo Serrano, Ariza-Montes e Sianes (2019) baseia-se na definição de um vetor de busca para que sejam recuperadas exclusivamente as investigações de interesse do pesquisador. Este método evita, por exemplo, a construção de bancos de dados muito amplos, que abranjam literaturas que não possuem, de fato, relação com a área do conhecimento investigada, permitindo, assim, a obtenção de resultados mais precisos e fidedignos. Desse modo, no nosso caso, escolheu-se o vetor de pesquisa "muse" que pôde garantir a detecção das produções que contemplassem as variantes relacionadas ao tema museus, como: "museu", "museologia", "museal", "museólogo", "musealização", etc.

É importante ressaltar que outros vetores não foram considerados para a busca de investigações, pois entendeu-se que com o vetor selecionado, já conseguiríamos recuperar todas as investigações relacionadas ao tema museus e informação. Não fazia sentido, por exemplo, realizar também uma busca considerando vetores de pesquisa ligados ao termo "informação", pois estando as produções científicas localizadas em anais de um evento da própria área de abrangência da $\mathrm{Cl}$ a sua conexão com a temática já é intrínseca.

Outra estratégia para a busca de investigações foi a de procurar pelo vetor "muse", unicamente nos títulos e subtítulos das produções dos anais do evento. Dois motivos principais resultaram nesta tática. O primeiro deles é o de que, segundo Curty e Boccato (2005), o título de um artigo é o termo ou expressão indicativa do seu conteúdo principal e, os subtítulos, quando existentes, trazem uma complementação ao título, visando, igualmente, esclarecer o assunto determinante da pesquisa. Assim, como títulos e subtítulos conseguem expor a temática principal de investigações, através de uma triagem por meio destes, é possível detectar aquelas produções que se destinaram a abordar o fenômeno museal e sua relação com a Ciência da Informação.

O segundo motivo, perpassa pela observação das pesquisadoras deste artigo que ao ler as palavras-chaves de algumas das produções relacionados ao tema "museus e informação", na grande maioria das vezes, quando o vetor 
"muse" estava presente nestas, encontrava-se, também, em seu título e/ou subtítulo. Acredita-se, nesse sentido, que o banco de dados construído não seria de grande divergência caso considerássemos uma busca somente pelo conteúdo dos títulos e subtítulos das investigações. Ou seja, entendeu-se que não seria necessário incluir as palavras-chaves das investigações como parte da estratégia de busca pelo vetor de pesquisa, pois a recuperação em exclusividade nos títulos e subtítulos foi percebida como eficaz no atendimento aos critérios e objetivos propostos nesta análise.

Assim, no dia 15/12/2019 iniciou-se o segundo passo desta investigação, resumindo-se no acesso ao portal do $\mathrm{ENANCIB}^{1}$, objetivando a triagem e recuperação de artigos, pôsteres e comunicações científicas variadas do evento desde 2007 a 2019, que contemplassem o vetor de pesquisa descrito nos parágrafos anteriores em seus títulos e/ou subtítulos. Após a seleção das investigações, fora construído um banco de dados, através do programa Microsoft Office Excel abrangendo as produções escolhidas. O banco contemplou três informações básicas de cada uma delas: a) o seu título; b) o grupo de trabalho pertencente; c) nome dos autores. Ao todo foram recuperadas e tabuladas 180 pesquisas, todas em português - língua oficial do evento.

Após a finalização da construção do banco de dados utilizou-se o programa NVivo para a estruturação e organização do conteúdo - Passo 3 . O NVivo configura-se como um software que suporta métodos variados de pesquisa, projetado para auxiliar o pesquisador na organização e análise de dados estruturados ou não, como: entrevistas, respostas abertas de pesquisa, artigos, mídia social, conteúdo web e bancos de dados diversos (LAGE, 2011).

A maior vantagem da utilização do programa NVivo nesta pesquisa foi a de minimizar o tempo adotado para a análise dos dados. Isso porque, o software é capaz de auxiliar na organização da informação do banco importado, facilitando a gestão do material inserido nele. Com isso, o NVivo permite a descoberta de conexões em relação aos dados de pesquisas através de gráficos e fluxogramas, levando a inferência de novas informações que demandariam

\footnotetext{
${ }_{1}^{1}$ Disponível em: <enancib.ibict.br>; Acesso em: 15/12/2019.
} 
esforços maiores dos pesquisadores caso fossem feitas sem o programa.

Um exemplo de funcionalidade do Nvivo utilizada para a elaboração da investigação foi a estruturação dos "nós". Um "nó", segundo Lage (2011) corresponde a uma estrutura para armazenamento de informações codificadas e pode assumir significados diferentes, dependendo da abordagem metodológica utilizada na pesquisa. No nosso caso, a título de exemplo, utilizamos os nós para suportar a análise de conteúdo do banco de dados. Através deles foi possível delimitar quais dos 180 estudos recuperados possuíam as temáticas mais semelhantes - por meio da estruturação agrupada das palavras-chaves dos títulos das investigações, que resumiram as principais abordagens de cada pesquisa, conectando as similares. Foi possível também, identificar os autores que mais publicaram sobre o tema museus e informação nos últimos 13 anos - a partir da construção dos nós de frequência da aparição de cada autor com o passar dos anos.

Outro exemplo referente ao uso dos nós baseia-se na observação das palavras-chaves mais citadas nos títulos - o que viabilizou a construção de um mapa de palavras que permitiu a melhor observação dos domínios mais estudados em se tratando da relação museus e informação. Neste caso é importante ressaltar que, para obter com clareza as palavras que resumiriam as principais abordagens, foram retiradas do banco de dados as palavras conectoras - preposições, conjunção, advérbios e até mesmo alguns verbos que de nada ajudariam a esclarecer as subdisciplinas de interesse dentro da área de estudo. Neste momento, foram retiradas também do banco de dados as palavras "informação (ções) " e todas as ligadas ao vetor "muse", para que então se obtivesse um mapa de palavras que revelasse o que tem sido mais estudado dentro do universo de museus e informação. Caso contrário, essas palavras permaneceriam como as de maior frequência de aparição, não delimitando corretamente os domínios de estudo buscados neste momento.

Assim, com todo o banco de dados organizado e sistematizado em informações agrupadas, foi possível realizar a análise cienciométrica referente a área de estudo "museus e informação" a partir dos anais do ENANCIB. 


\section{RESULTADOS}

Em se tratando do volume de investigações do evento ENANCIB que se destinaram a pesquisar sobre a relação "museus e informação", é perceptível conforme Gráfico 1 - a existência de uma tendência ascendente relacionada a esta área do conhecimento quando comparamos os resultados desde o ano de 2007 até 2019.

Os anos de 2007 e 2008, por exemplo, foram aqueles com o menor número de publicações, com duas e cinco, respectivamente. Entretanto, no ano de 2009, verifica-se um salto em relação ao número de pesquisas dentro desta área do conhecimento, já que, o volume de investigações triplica quando comparado ao ano anterior. O motivo desta ascensão, pode provavelmente ser justificado, por este ter sido o ano de abertura do GT9, quando os pesquisadores de museus tiveram a chance de publicação em um GT específico da área.

\section{Gráfico 1: Número de investigações que relacionaram "museus e informação" no ENANCIB (2007 - 2019)}

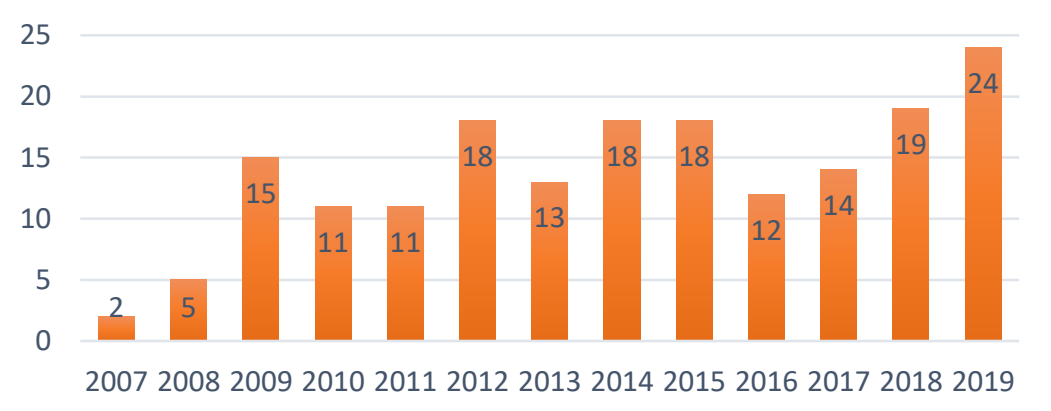

Fonte: Dados de pesquisa (2020)

Outra observação importante em se tratando do Gráfico 1 reconfirma o aumento do volume da produção científica relacionada a museus e informação no evento. Isso porque, se compararmos a média aritmética de publicação dos sete primeiros anos de estudo (2007-2013), identificaremos o resultado de 10,7 artigos publicados por ano, o que é consideravelmente menor do que a média aritmética dos últimos sete anos de evento (2013-2019), que se resume a 16,8 pesquisas por ano. Com essas informações, pode-se inferir que o tópico de museus dentro do maior evento de $\mathrm{Cl}$ no Brasil está em crescimento mesmo detendo alguns anos com menores índices de publicação do que outros. 
O Gráfico 2, apresenta a frequência de aparição de publicações relacionadas a museus nos grupos de trabalho do ENANCIB. Através dele, é possível deduzir quais são as principais abordagens de trabalho dos pesquisadores que estudam a relação dos museus associada a informação.

\section{Gráfico 2: Aparição de publicações relacionadas a museus por GT do ENANCIB nos últimos 13 anos}

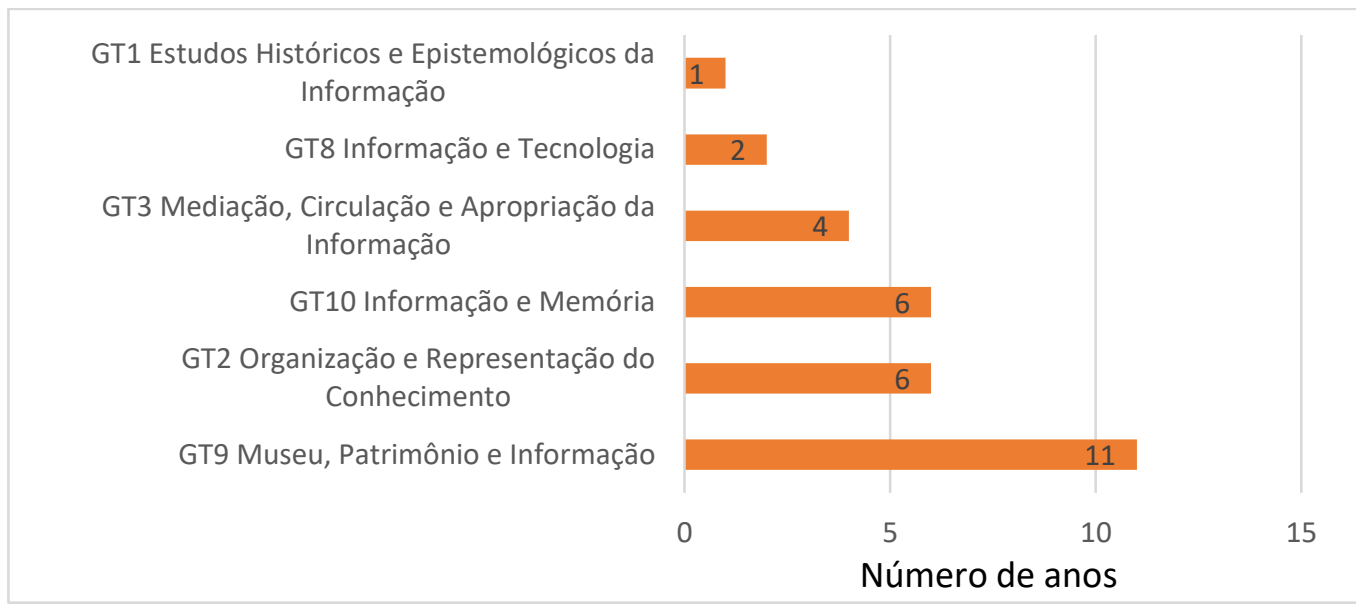

Fonte: Dados de pesquisa (2020)

Pode-se perceber, que o GT9 é soberano em frequência de publicações. Ele aparece em todos os anos com publicações referentes ao tema, com exceção dos anos de 2007 e 2008, quando o GT ainda não existia, por isso a sua constância em 11 dos 13 anos estudados do evento. Um exemplo de pesquisa contemplada neste GT pode ser observado pelo artigo "O Museu de Arte Sacra de Paraty: a patrimonialização e suas novas perspectivas" de Dantas e Uzeda (2015), que traz um novo olhar referente a patrimonialização e a documentação em museus, revelando a vivência funcional do acervo do Museu de Arte Sacra de Paraty que é retirado de seu espaço para ser utilizado nas manifestações religiosas na cidade.

O segundo grupo de trabalho com maior número de publicações associadas a museus é o GT2. O GT aparece em seis dos 13 anos de pesquisa estudados, demonstrando que o assunto possui ligação com a temática de museus e informação. Um exemplo de pesquisa publicada no GT é a "CRM, FRBR e RiC: o alinhamento semântico de acervos de museus, bibliotecas e arquivos" de Bezerra, Fonseca e Marcondes (2017). O artigo aborda a utilização de modelos para promover a representação de acervos digitais que favoreçam 
o desenvolvimento de plataformas universais à disposição da sociedade.

Além do GT2, outro GT possui a frequência de seis anos em 13 com pesquisas relacionadas a museus, o GT10. Um exemplo de pesquisa realizada e publicada dentro deste grupo de trabalho pode ser observada pelo artigo "Informação e memória indígena no boletim do museu paraense Emílio Goeldi.Ciências Humanas" de Paiva, Ramalho e Carvalho (2015), que visa responder ao questionamento de como tem sido construída a memória registrada dos povos indígenas entre os fascículos do Boletim do Museu Paraense Emílio Goeldi.Ciências Humanas.

O GT3 aparece em quatro dos 13 anos de estudo. Um exemplo de artigo contemplado neste GT é "A mediação cultural como ferramenta de comunicação nos museus de ciências" de Braga e Crippa (2011). Os dois últimos GT's são o GT8 com aparição em dois dos 13 anos e o GT com aparição em um dos 13 anos de estudo. Exemplos de artigo desses grupos de trabalho são: "Imagem \& tecnologia em catálogos de museus de arte: intersemiose em questão" de Lima e Santos (2014) e "Museus, Informação e Cultura Material: o desafio da Interdisciplinaridade" de Loureiro, Loureiro e Silva (2008), respectivamente.

Dando continuidade ao esforço em se detectar as principais temáticas abordadas pelos pesquisadores da área de estudo de "museus e informação" no evento ENANCIB, a Figura 2 traz um mapa de palavras referente as palavras mais citadas nos títulos e subtítulos das 180 publicações recuperadas e trabalhadas neste estudo.

Figura 2: Mapa de palavras das publicações relacionadas a "museus e informação" no ENANCIB

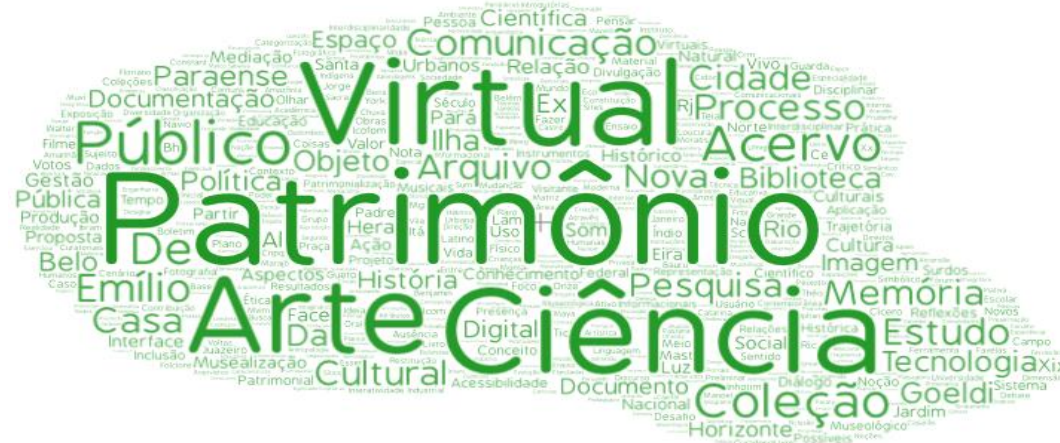

Fonte: Dados de pesquisa (2020) 
Através do mapa, podemos reforçar a ideia de quais são as principais abordagens das investigações pesquisadas por meio deste estudo cienciométrico. A palavra "patrimônio", por exemplo, é a que mais aparece em frequência nos títulos dos artigos e pôsteres estudados, seguida das palavras "ciência", "virtual", "arte", "público", "coleção", "comunicação", "acervo", "documentação", etc.

Podemos inferir, nesse caso, que o estudo de museus e informação nos anais do ENANCIB está ligado, por exemplo, a sua relação com o patrimônio, a representação das instituições museais em ambientes virtuais, ao estudo de seus públicos, a pesquisas no âmbito das suas coleções e acervos, a prática da documentação museológica, dentre vários outros.

Conforme comentado anteriormente, essas palavras, que recorrem a determinadas temáticas podem ser chaves para a conscientização dos principais hot topics trabalhados em se tratando de museus e informação nos anos de produção científica do evento ENANCIB. A partir do mapa de palavras, nesse sentido, é possível a delimitação de para onde estão caminhando os estudos relacionados a nossa temática de interesse, quais os mais frequentes e quais são aqueles que ainda podem ser mais trabalhados.

Sobre este último caso, por exemplo, pode-se refletir sobre novas produções científicas ligadas a qualidade da informação em museus, por exemplo, a sua relação com as novas tecnologias como os aplicativos de museus e a interatividade do seu acervo de um modo geral, além do uso estratégico de analises de grandes bases de dados para melhoria dos seus processos internos, como os estudos de Big Data, etc.

Entende-se que essas temáticas podem ser trabalhadas em maior profundidade em vista de sua aparição em poucos dos títulos estudados neste artigo, o que denota interesse de alguns pesquisadores, porém, ainda sem grande difusão se considerarmos a amostra de pesquisa estudada. Se forem, por exemplo, identificadas necessidades de evolução desses domínios para o desenvolvimento das instituições museais e de suas atividades, órgãos de fomento ou universidades poderão manejar esforços para o avanço de estudos nessas áreas do conhecimento.

Nesse âmbito, é possível, ainda, observar, quando analisamos o Gráfico 
3 - que aborda os assuntos mais estudados entre as pesquisas que relacionam os temas de museus e informação - resultados semelhantes aos concebidos através da Figura 2, e novas informações que contribuem para a delimitação das temáticas chaves referentes ao campo de estudo analisado neste artigo.

\section{Gráfico 3: Domínios de interesse: os assuntos mais estudados entre as pesquisas relacionadas a "museus e informação" no ENANCIB}

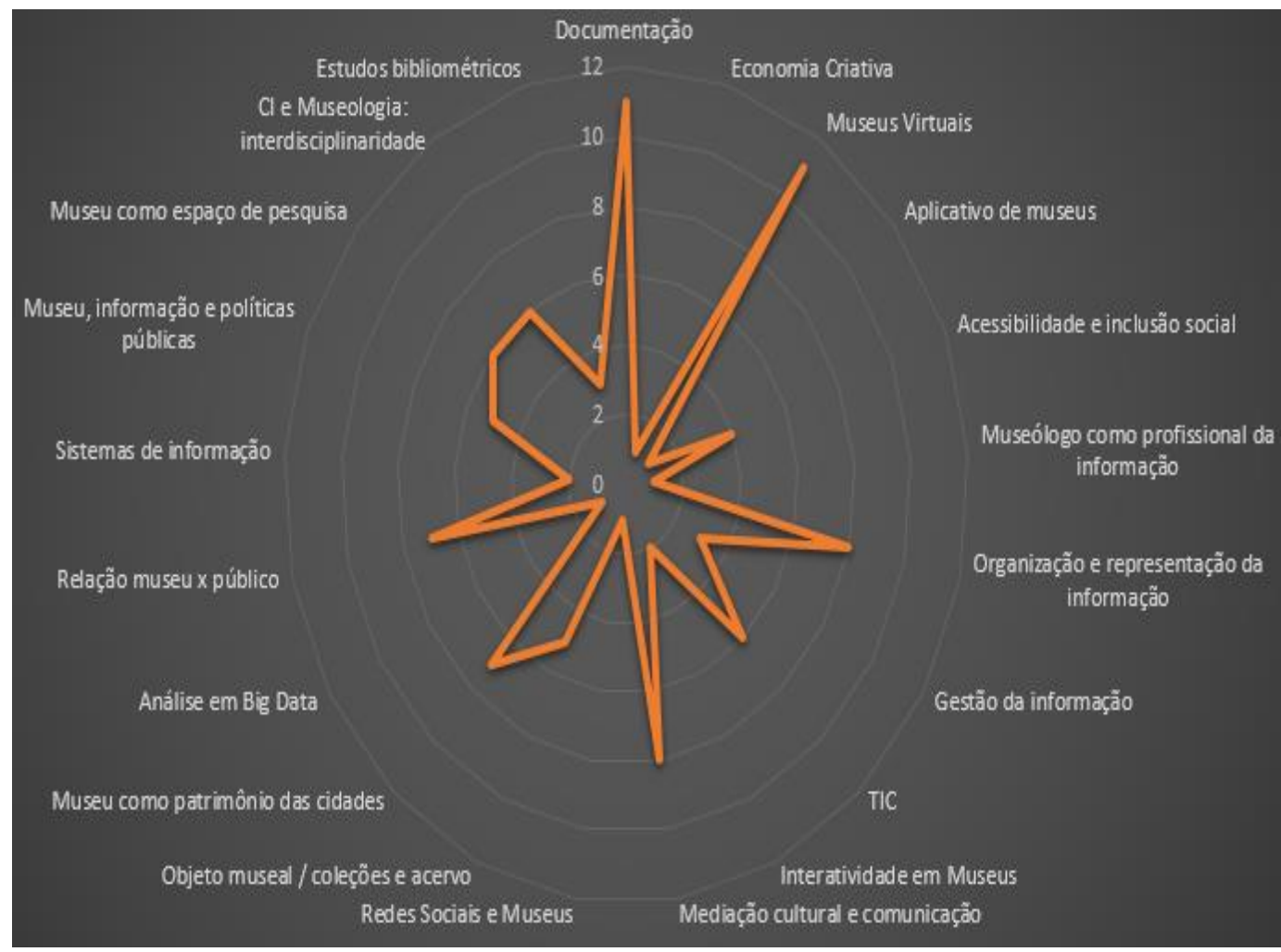

Fonte: Dados de pesquisa (2020)

Por meio deste gráfico, observa-se que os domínios "Documentação Museológica" e "Museus Virtuais" são aqueles mais pesquisados, seguidos da "Organização e representação da informação", "Mediação Cultural e comunicação", "Relação museu x público", "Museu como patrimônio das cidades", "Tecnologias da Informação e Comunicação - TIC", "Cl e Museologia: interdisciplinaridade", "Museu como espaço de pesquisa" e "Museu, informação e políticas públicas". Estas se configuram como as dez temáticas principais abarcadas pelo estudo de museus e informação no evento ENANCIB.

Assuntos como "Objeto museal / coleções e acervo", "Acessibilidade e inclusão social", "Gestão da informação", "Estudos bibliométricos", "Sistemas de informação" e "Interatividade em Museus" foram estudados pelos autores 
participantes do evento medianamente, aparecendo entre cinco e dois estudos em relação a frequência. Temas como "Análise em Big Data", "Museólogo como profissional da informação", "Redes Sociais e Museus", "Aplicativo de museus" e "Economia Criativa" foram os menos trabalhados aparecendo uma única vez.

O Quadro 1 auxilia na análise desses domínios de estudo em um caráter cronológico, corroborando para a compreensão evolutiva das temáticas de trabalho que relacionaram museus e informação ao longo dos anos de evento. Para isso, optou-se por dividir os 13 anos em três períodos principais com o objetivo de facilitar a análise dos dados: 1) primeiro período: 2007-2010; 2) segundo período: 2011-2015; 3) terceiro período 2016-2019.

\section{Quadro 1 - Evolução dos principais domínios de estudo do evento ENANCIB relacionados a "museus e informação" nos últimos 13 anos}

\begin{tabular}{|c|c|c|c|c|c|c|c|c|c|c|c|c|c|c|}
\hline & Anos de publicação & 2007 & 2008 & 2009 & 2010 & 2011 & 2012 & 2013 & 2014 & 2015 & 201 & 2017 & 2018 & 2019 \\
\hline & Redes Sociais e Museus & & & & & & & & & & & & & $\mathrm{x}$ \\
\hline & Aplicativo de museus & & & & & & & & & & & & & $x$ \\
\hline & Economia Criativa & & & & & & & & & & & & $x$ & \\
\hline & Análise em Big Data & & & & & & & & & $\mathrm{x}$ & & & & \\
\hline & Museu como espaço de pesquisa & & & & & & & $x$ & & $x$ & $x$ & $x$ & $x$ & $x$ \\
\hline & Sistemas de informação & & & & & & $x$ & & & $x$ & & & & \\
\hline & Museu, informação e políticas & & & & & & & & & & & & & \\
\hline & públicas & & & & & & $\mathrm{x}$ & $\mathrm{x}$ & & & $\mathrm{X}$ & & $\mathrm{x}$ & $\mathrm{x}$ \\
\hline & Gestão da informação & & & & & $x$ & & & & & & $x$ & & $x$ \\
\hline & Acessibilidade e inclusão social & & & & & $x$ & & & $x$ & $x$ & & & $x$ & \\
\hline 운 & Interatividade em Museus & & & & & $x$ & & & & & & & & $x$ \\
\hline$\frac{1}{2}$ & Mediação cultural e comunicação & & & & & $x$ & $x$ & $x$ & & $x$ & $x$ & $x$ & $x$ & $x$ \\
\hline d & Museu como patrimônio das & & & & & & & & & & & & & \\
\hline$n$ & cidades & & & $x$ & & & & $x$ & & $x$ & $\mathrm{X}$ & $\mathrm{X}$ & $x$ & $\mathrm{X}$ \\
\hline $.0 \frac{0}{c}$ & Estudos Bibliométricos & & & $x$ & $x$ & & & & & & & & $x$ & \\
\hline 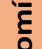 & Museus Virtuais & & & $\mathrm{x}$ & $x$ & $x$ & $x$ & $x$ & $x$ & $x$ & $x$ & $x$ & $\mathrm{x}$ & $x$ \\
\hline & Objeto Museal /coleções e acervo & & & $x$ & & & & & & $x$ & $x$ & $x$ & $x$ & \\
\hline & Documentação & & & $x$ & $x$ & $x$ & $x$ & $x$ & $x$ & $x$ & $x$ & $x$ & $x$ & $x$ \\
\hline & $\begin{array}{l}\text { Cl e Museologia: } \\
\text { interdisciplinaridade }\end{array}$ & & $\mathrm{x}$ & $\mathrm{x}$ & & $\mathrm{x}$ & $\mathrm{x}$ & & $\mathrm{x}$ & & & & $\mathrm{x}$ & \\
\hline & $\begin{array}{c}\text { Museólogo como profissional da } \\
\text { informação }\end{array}$ & & $\mathrm{x}$ & & & & & & & & & & & \\
\hline & $\begin{array}{l}\text { Tecnologias da informação e } \\
\text { comunicação }\end{array}$ & $\mathrm{x}$ & & & & $\mathrm{x}$ & & & $\mathrm{x}$ & & $\mathrm{x}$ & & $\mathrm{x}$ & $\mathrm{x}$ \\
\hline & Relação museu x público & $x$ & & $x$ & & & $x$ & & $x$ & $x$ & $x$ & & & $x$ \\
\hline & $\begin{array}{l}\text { Organização e representação da } \\
\text { informação }\end{array}$ & $\mathrm{x}$ & & & & & & $\mathrm{x}$ & $\mathrm{x}$ & $\mathrm{x}$ & $\mathrm{x}$ & $\mathrm{x}$ & $\mathrm{x}$ & $\mathrm{x}$ \\
\hline
\end{tabular}

Fonte: Dados de pesquisa (2020)

No primeiro período (2007-2010) pode-se observar uma tendência de 
estudo pelos autores participantes do evento de temáticas que objetivam compreender com maior profundidade conceitos das disciplinas de Museologia e $\mathrm{Cl}$, e como tem se dado a sua relação de uma forma geral. Isso pode ser observado pelas pesquisas dedicadas a estudos bibliométricos, bem como, àquelas voltadas a pesquisas de interdisciplinaridade e ao reconhecimento do papel do profissional da informação ligado a museus.

Para Serrano, Ariza-Montes e Sianes (2019) - que são responsáveis pelo desenvolvimento de um estudo bibliométrico acerca do tema "turismo sustentável"- normalmente, quando do início da construção teórica de uma disciplina ou área do conhecimento, as produções científicas parecem ser mais ligadas a questões relacionadas ao entendimento daquele saber, suas relações teóricas e práticas, a partir da construção de conceitos e conexões.

Além disso, domínios de estudo que aparecem no primeiro período trabalhado, como a relação museus $\mathrm{x}$ público, as coleções e acervos, documentação, organização e representação da informação e museus virtuais se configuram como temas chaves apresentados nos primeiros quatro anos de eventos, mas que se desenrolam até os dias atuais, o que sugere estarmos tratando de uma abordagem ainda não suficientemente amadurecida, pois não parecem haver domínios já exaustivamente estudados e finalizados com os 13 anos de estudo do evento.

Em relação ao segundo período (2011-2015) percebe-se a forte permanência de alguns domínios de estudo como os museus virtuais e a documentação - presentes em todos os anos de pesquisa - assim como a relação museu x público, a interdisciplinaridade e a organização e representação da informação. Por outro lado, surgem novas abordagens com o passar dos anos como a mediação cultural e comunicação, a acessibilidade e inclusão social, a gestão da informação e a relação do museu com as políticas públicas.

Os novos tópicos de estudo denotam um crescimento do debate relacionado a área de estudos de museus e informação, além de expor novas necessidades de pesquisas a partir de mudanças nas realidades das instituições museais, por exemplo. A mediação cultural e a acessibilidade retomam a ideia de inclusão social e educação em museus, por outro lado a gestão da informação e a aproximação de 
estudos relacionados a políticas públicas revelam uma tendência mais corporativa e organizacional abarcada pelos gestores dessas instituições. Já no final do período, em 2015, surge o tema Big Data em museus acompanhando uma tendência de pesquisa mundial, inclusive para outras áreas do conhecimento.

No terceiro período (2016-2019) pode-se observar tanto a emersão de novos tópicos quanto a conservação e desaparecimento de outros. Vê-se, por exemplo, que domínios como os da organização e representação da informação, a documentação, os museus virtuais e a mediação cultural e comunicação em museus permanecem como tópicos vivos de discussão durante todo o último período, sendo, certamente os assuntos de maior abrangência quando relacionamos as disciplinas de Museologia e Ciência da Informação.

Por outro lado, é importante ressaltar que saberes como a interdisciplinaridade entre Museologia e $\mathrm{Cl}$ e o estudo do museólogo como profissional da informação basicamente deixam de ser estudados neste último período. Isto pode dizer que estes assuntos remetem a questões um pouco mais esclarecidas na área do conhecimento estudada e, por isso, já não tem sido de tanta preocupação dos pesquisadores que se destinam a estudar museus e sua relação com a informação.

Novos domínios surgem ao final deste período como a temática da economia criativa, dos aplicativos de museus e das redes sociais e museus, notadamente assuntos que evoluíram conforme a própria ascensão tecnológica da sociedade e as novas demandas ligadas ao público de instituições culturais.

Seguindo adiante, outro ponto importante a ser tratado neste estudo é o da distribuição do número de publicações científicas por autores participantes do evento, isto é, sua produtividade. Neste caso, pode-se observar que há uma desigualdade de produtividade entre os autores que estudam "museu e informação". Isso porque, a maioria dos autores, conforme se pode observar no Gráfico 4, é responsável pela publicação do menor número de obras normalmente publicaram uma única vez no ENANCIB - enquanto alguns poucos autores são os responsáveis pela maior parte da literatura relevante sobre o assunto, formando um grupo mais prolífico.

Por meio do Gráfico 4, pode-se constatar que enquanto um autor 
individualmente publicou 15 artigos durante os 13 anos de evento, ou seja, mais de uma produção por ano, e outros dois autores, individualmente publicaram 14 artigos cada, a grande maioria - 143 autores - publicaram somente um artigo durante todos os anos de análise do evento.

Gráfico 4: Número de publicações por número acumulado de autores com temática relacionada a "museus e informação"

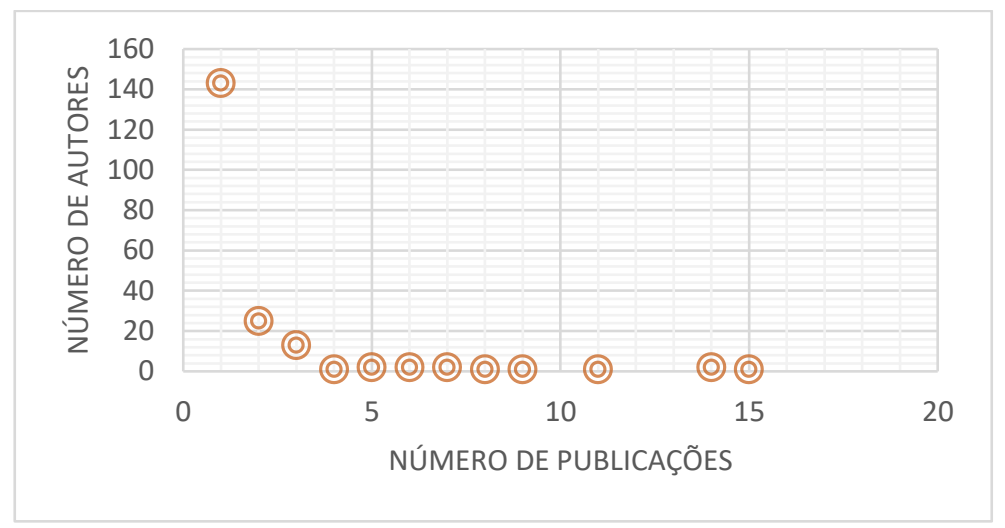

Fonte: Dados de pesquisa (2020)

Para melhor observação do grupo de autores com maior número de publicações referente a temática estudada, o Gráfico 5 traz um ranking com aqueles pesquisadores com maior produtividade no evento ENANCIB. A representatividade destes para o período corresponde a quase $30 \%$ do total de publicações lembrando que estes podem realizar coautoria em um ou vários artigos científicos.

\section{Gráfico 5: Os 10 autores que mais publicaram no ENANCIB com temática relacionada a museus e informação}

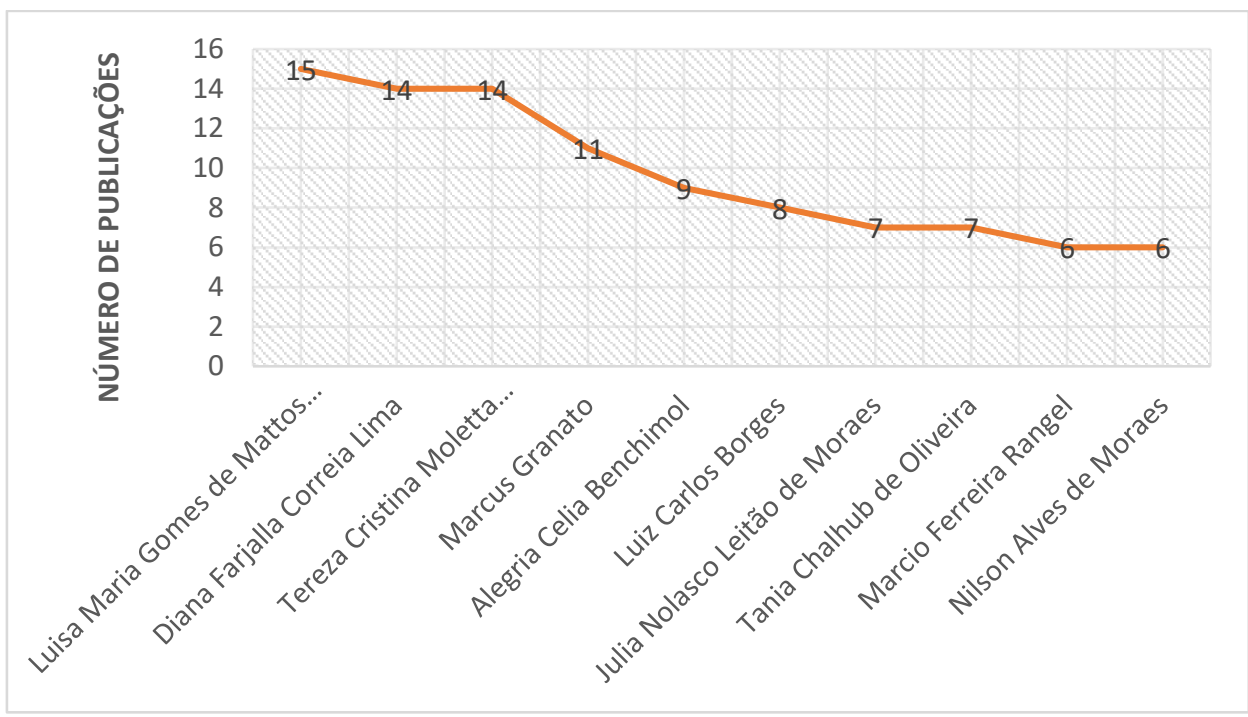

Fonte: Dados de pesquisa (2020) 
Em se tratando de coautorias ou pesquisas realizadas individualmente, das 180 investigações trabalhadas, $27,78 \%$ foram realizadas por um único autor cada, e $72,22 \%$ foram conduzidas por dois autores ou mais, conforme podemos observar a partir do Gráfico 6.

Dos $72,22 \%$ de trabalhos construídos em coautoria $57,22 \%$ foram realizados com dois autores, $12,78 \%$ com três autores, $1,67 \%$ com quatro autores e $0,56 \%$ com sete autores. Para esta amostra não foram identificadas investigações em coautoria com cinco ou seis pesquisadores.

Esse resultado revela que em relação a temática de estudos abordada neste artigo a grande maioria da produção científica é realizada em conjunto, com pelo menos, uma parceria entre dois investigadores.

É ainda importante ressaltar que, do total de autores contemplados em todas as 180 produções científicas, $69 \%$ são mulheres e, $31 \%$ homens, o que revela uma predominância do sexo feminino no estudo da área de conhecimento trabalhada.

\section{Gráfico 6: Pesquisas individuas e em coautoria no ENANCIB com temática relacionada a museus e informação}

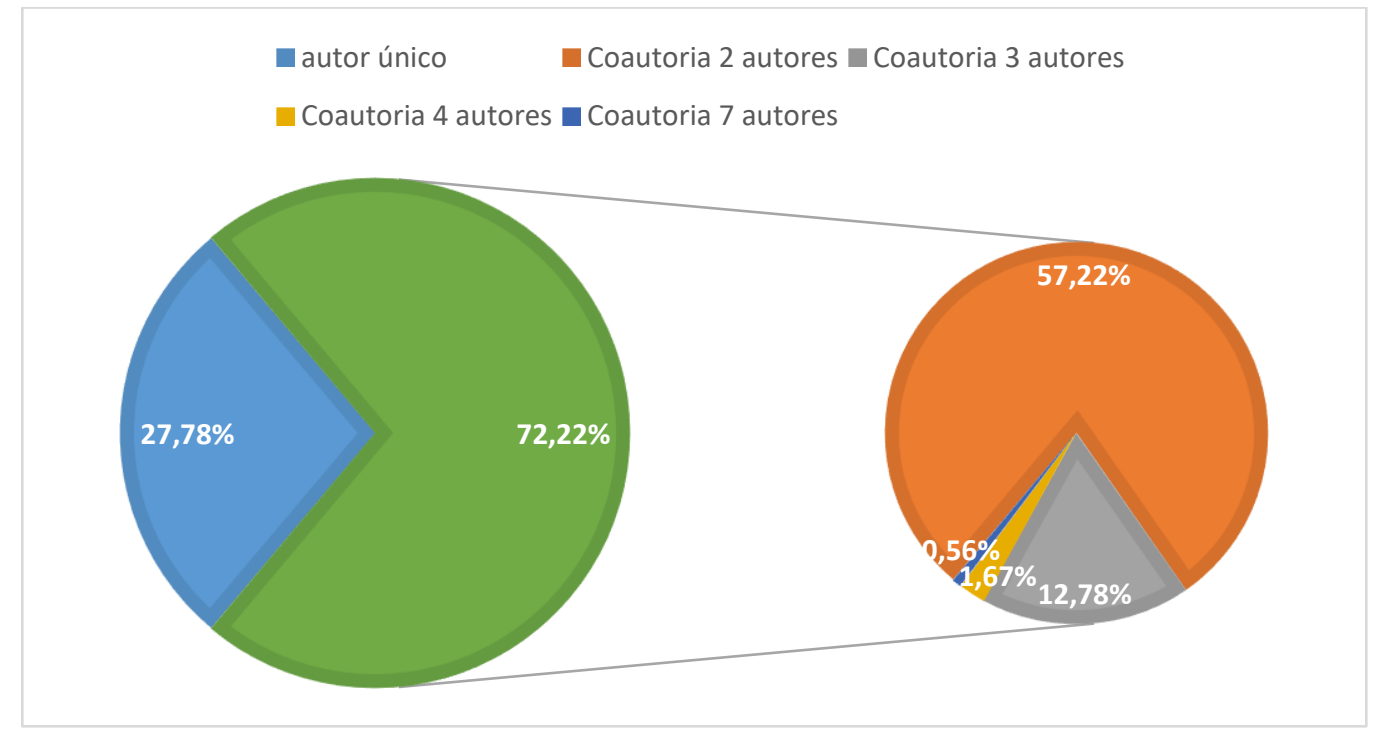

Fonte: Dados de pesquisa (2020)

Deste modo, a partir dos resultados exibidos acima, apresentaremos a seguir algumas considerações referente ao estudo realizado. 


\section{CONSIDERAÇÕES FINAIS}

O objetivo deste estudo foi contribuir para o entendimento das principais tendências de pesquisa sobre museus e informação no Brasil a partir de uma análise cienciométrica realizada nos anais do ENANCIB. Com isso, tivemos como propósito a promoção do debate acadêmico sobre as abordagens predominantes de pesquisa ligadas a esta área do saber e sua evolução, oferecendo uma ideia cronológica da produção científica no campo desde a publicação dos primeiros artigos ligados ao tema no evento até o ano de 2019.

Viu-se, nesse sentido, que as temáticas da "Documentação Museológica" e "Museus Virtuais" são, respectivamente, aquelas mais pesquisadas dentro do período de tempo observado. Novos domínios de estudo também foram revelados com a pesquisa, como a relação dos museus com a temática da Economia Criativa, dos Aplicativos de Museus e das Redes Sociais, refletindo o nascimento de assuntos que evoluíram conforme a própria ascensão tecnológica da sociedade e as novas demandas ligadas ao público de museus. É importante ressaltar, a partir disso, que o surgimento de temas emergindo da combinação de questões existentes e suas interações é uma consequência inerente ao processo de desenvolvimento de um campo de pesquisa, que caminha conforme as necessidades sociais dos indivíduos e instituições, objetivando a resolução de conflitos que se apresentam dentro da sua área do conhecimento.

Os resultados do estudo baseado em técnicas cienciométricas, nesse sentido, refletem a evolução da estrutura conceitual da área de pesquisa "museu e informação" reafirmando a importância de alguns domínios e o desaparecimento e surgimento de outros. Dessa forma, a análise foi capaz de identificar lacunas que poderão se tornar novas possibilidades de pesquisa na arena da Museologia aliada a $\mathrm{Cl}$ - o que denota uma área do conhecimento ainda aberta a novas discussões e debates. Por outro lado, conseguiu-se delimitar campos de estudo mais estáveis e também obsoletos, permitindo contribuir com os pesquisadores que se destinam a desenvolver investigações ligadas a esta temática, a partir do maior entendimento do campo em que se destinaram a estudar. Isso nos leva a acreditar que a metodologia de trabalho 
proposta fora adequada para os objetivos delineados.

Percebeu-se ainda que, em se tratando de volume de pesquisas referentes a temática estudada no evento ENANCIB é perceptível a existência de uma tendência ascendente relacionada a esta área do conhecimento. Identificou-se, também, uma desigualdade de produtividade entre os autores que estudam o tema. Isso porque, a maioria destes, é responsável pela publicação do menor número de obras, enquanto poucos são responsáveis pela maior parte da literatura relevante sobre o assunto.

Em relação as limitações do estudo podemos citar a base de dados utilizada, ligada estritamente a um evento na área de $\mathrm{Cl}$. Para pesquisas futuras, refletimos quanto a possibilidade de abertura das buscas de literaturas para base de dados online, como por exemplo, o Web of Science, o SCOPUS, etc. Podese, inclusive, expandir a variabilidade de estudos, adicionando produções científicas em outras línguas, além de diversificar os tipos de documentos inseridos no banco de dados, a exemplo de teses e dissertações. Essas estratégias poderão complementar os resultados finais, possibilitando o alcance de conclusões que reflitam melhor a evolução da temática abordada. Além disso, pode-se cogitar a inserção de estatísticas relacionadas a colaboração de pesquisas entre instituições (universidade e demais órgãos) e autores (análises aprofundadas de coautoria e colaborações diversas), o que também poderá proporcionar uma maior riqueza de detalhes para os resultados.

Outra dificuldade encontrada ao longo desta investigação se deve ao fato de não termos encontrados estudos cienciométricos semelhantes na área de pesquisa de museus e informação para fins comparativos. O que, de certa forma, também pode ser encarado pelo lado da originalidade do estudo.

Entende-se, nesse sentido, que o artigo contribuiu para elucidar as possibilidades de novos roteiros de investigação nos campos de Museologia e Ciência da Informação, tendo potencial para cooperar na melhoria dos processos institucionais dos museus, bem como no melhor atendimento do seu público.

A importância do estudo exposto perpassa pela ideia de que a avaliação da produtividade científica deve ser um dos elementos principais para 0 estabelecimento e acompanhamento de uma política nacional de ensino e 
pesquisa, uma vez que permite um diagnóstico das potencialidades e possibilidades do campo de saber estudado. Sabe-se, entretanto, que ainda faltam subsídios para o completo delineamento desta área do conhecimento, o que não se contrapõe ao fato de que um passo foi dado em busca da construção do entendimento das principais tendências de pesquisa em torno da relação entre "museus e informação" no país.

\section{REFERÊNCIAS}

BERTUZZO, G. M. P. Produção Científica: um estudo cienciométrico do periódico Turismo em Análise.SEMINÁRIO DE PESQUISA EM TURISMO DO MERCOSUL, 2., 2004. Anais [...] [s.I.], 2004. Disponível em: https://www.ucs.br/site/midia/arquivos/30-producao-cientifica.pdf. Acesso em: 20 jan. 2020.

BEZERRA, D. A.; FONSECA, V. M. M.; MARCONDES, C. H. CRM, FRBR e RIC: 0 alinhamento semântico de acervos de museus, bibliotecas e arquivos. In: ENCONTRO NACIONAL DE PESQUISA EM CIÊNCIA DA INFORMAÇÃO (ENANCIB), 18., 2017 Anais [...] Marília: ANCIB; Unesp, 2017.

BRAGA, J.; CRIPPA, G. A mediação cultural como ferramenta de comunicação nos museus de ciências. In: ENCONTRO NACIONAL DE PESQUISA EM CIÊNCIA DA INFORMAÇÃO (ENANCIB), 12., 2011 Anais [...] Brasília: ANCIB; UnB, 2011.

CURTY, M. G.; BOCCATO, V. R. C. O artigo científico como forma de comunicação do conhecimento na área de Ciência da Informação. Perspect.

Ciênc. Inf., Belo Horizonte, v.10 n.1, p. 94-107, jan./jun. 2005.

DANTAS, J. C. N.; UZEDA, H. C. O Museu de Arte Sacra de Paraty: a patrimonialização e suas novas perspectivas. In: ENCONTRO NACIONAL DE PESQUISA EM CIÊNCIA DA INFORMAÇÃO (ENANCIB), 16., 2015 Anais [...] João Pessoa: ANCIB; UFPB, 2015.

DOBROV, G. M.; KARENNOI, A. A. The informational basis of scientometrics. In: MIKHAILOV, A. I. (Ed.). On theoretical problems of informatics. Moscou: VINITI./FID, 1969. p. 165-191.

ENANCIB, Encontro Nacional de Pesquisa em Ciência da Informação. Disponível em:enancib.ibict.br/index.php/enancib/index. Acesso: 10 jan. 2020. 
LAGE, M. C. Utilização do software NVivo em pesquisa qualitativa: uma experiência em EaD. ETD - Educação Temática Digital, v. 12, n. especial, p. 198-226, mar.2011.

LIMA, F. R. B.; SANTOS, P. L. V. A. C. Imagem \& tecnologia em catálogos de museus de arte: intersemiose em questão. In: ENCONTRO NACIONAL DE PESQUISA EM CIÊNCIA DA INFORMAÇÃO (ENANCIB), 15., 2014 Anais [...] Belo Horizonte: ANCIB; UFMG, 2014.

LOUREIRO, J. M. M.; LOUREIRO, M. L. N. M.; SILVA, S. D. Museus, Informação e Cultura Material: o desafio da Interdisciplinaridade. In: ENCONTRO NACIONAL DE PESQUISA EM CIÊNCIA DA INFORMAÇÃO (ENANCIB), 9., 2008 Anais [...] São Paulo: ANCIB; USP, 2008.

OLIVEIRA, A. C.; DÓREA, J. G.; DOMENE, S. M. A. Bibliometria na avaliação da produção científica da área de nutrição registrada no Cibran: período de 1984-1989. Ciência da Informação, Brasília, v. 21, n. 3, p. 239-242, set./dez. 1992.

PAIVA, E. B.; RAMALHO, F. A.; CARVALHO, E. T. G. Informação e memória indígena no boletim do Museu Paraense Emilio Goeldi.Ciências Humanas. In: ENCONTRO NACIONAL DE PESQUISA EM CIÊNCIA DA INFORMAÇÃO (ENANCIB), 16., 20015 Anais [...] João Pessoa: ANCIB; UFPB, 2015.

PRICE, D. J. S. Little Science, Big Science (O desenvolvimento da ciência). Trad. Simão Matias e Gilda Maria Braga. Rio de Janeiro. Livros técnicos e científicos Editora S.A 1975. 96p.

SANTOS, V. C. R. Gestão, Informação e Comunicação Museológica: um estudo comparativo entre pequenos e médios museus brasileiros e franceses. Tese (Doutorado em Ciência da Informação) - Escola de Ciência da Informação, Universidade Federal de Minas Gerais. Belo Horizonte, 2011.

SERRANO, L.; SIANES, A.; ARIZA-MONTES, A. Using Bibliometric Methods to Shed Light on the Concept of Sustainable Tourism. Sustainability, v. 11, n. 24, p. 1-25, 2019.

TAGUE-SUTCKIFFE, J. An introduction to informetrics. Information processing \& management, v. 28, n. 1, p. 1-3, 1992.

VANTI, N. A. P. Da bibliometria à webometria: uma exploração conceitual dos mecanismos utilizados para medir o registro da informação e a difusão do conhecimento. Ci. Inf. [online]. v.31, n.2, p.152-162, 2002.

\section{RESEARCH TRENDS ON MUSEUMS AND INFORMATION IN BRAZIL: A SCIENTOMETRIC STUDY FROM THE ANNALS OF THE ENANCIB}




\begin{abstract}
Introduction: The relationship between museums and information is highlighted worldwide since 1970, when meanings were added to museological objects that expanded their functions, such as the perception of their capacity to transmit varied information to the public. Thereafter, scientists linked to both the study of museums and research in information, began to develop investigations relating both areas of knowledge. Objective: Thus, the objective of this article is to understand the main research trends on museums and information in Brazil. Methodology: For this, a scientometric study was carried out from the congress proceedings of the National Research Meeting in Information Science from 2007 to 2019. A database composed of 180 scientific productions was generated and imported into the NVivo. The use of the program improved the analysis of the bank, enabling the construction of knowledge from the information collected. Results: Through the results, there was an upward trend in the number of publications related to the topic museums and information at the event in recent years. There was an inequality of productivity between the authors who study the topic, as few are responsible for most of the literature. It was also seen that the guidelines of greatest interest among researchers in this field are Museological Documentation and Virtual Museums. Conclusions: The article elucidates the possibilities of new research routes, which may assist in the development of incentive policies for the promotion of research that have not yet been done, but which need to be carried out when dealing with the topic of museums and information.
\end{abstract}

Descriptors: Museums. Information. Scientific Textual Production.

\title{
TENDENCIAS DE INVESTIGACIÓN SOBRE MUSEOS E INFORMACIÓN EN BRASIL: UN ESTUDIO CIENTÍMETRICO DE LAS ACTAS DEL ENANCIB
}

\begin{abstract}
RESUMEN
Introducción: La relación entre los museos y la información se destaca en todo el mundo a partir de 1970, cuando se añadieron significados a objetos museológicos que ampliaron sus funciones, como la percepción de su capacidad para transmitir información variada al público. A partir de ahí, los científicos vinculados tanto al estudio de los museos como a la investigación de la información comenzaron a desarrollar investigaciones relacionadas con ambas áreas del conocimiento. Objetivo: Por lo tanto, el objetivo de este artículo es entender las principales tendencias de investigación sobre museos e información en Brasil. Metodología: Para ello, se llevó a cabo un estudio scientométrico desde las actas del Encuentro Nacional de Investigación en Ciencias de la Información de 2007 a 2019. Se había generado e importado una base de datos compuesta por 180 producciones científicas al NVivo. El uso del programa mejoró el análisis del banco, permitiendo construir conocimiento a partir de la información recopilada. Resultados: A través de los resultados, hubo una tendencia al alza en el número de publicaciones relacionadas con el tema museos e información en el evento en los últimos años. Hubo una desigualdad en la productividad entre los autores que estudian la temática, ya que pocos son responsables de la mayor parte de la literatura. También se observó que las pautas de mayor interés entre los investigadores son la documentación museológica y los museos virtuales. Conclusiones: el artículo aclara las posibilidades de nuevas rutas de investigación, que pueden ayudar en el desarrollo de políticas de incentivos para la promoción de la investigación que aún no se han
\end{abstract}


realizado, pero que deben llevarse a cabo cuando se trata el tema de los museos y la información.

Descriptores: Museos. Informacion. Producción Textual Científica.

Recebido em: 08.03.2020

Aceito em: 04.08.2020 